\title{
The smoking attitudes, knowledge, intent, and behaviors of adolescents and young adults: I mplications for nursing practice
}

\author{
Barbara J. Ganley, Dianne I. Rosario \\ Dominican University of California, San Rafael, California \\ Correspondence: Barbara J. Ganley. Address: Dominican University of California. 50 Acacia Avenue, San Rafael, \\ California 94901. Telephone: 415-482-1829. Email: barbara.ganley@dominican.edu \\ Received: May 31, 2012 \\ DOI : 10.5430/jnep.v3n1p40 \\ Published: January 1, 2013 \\ URL: http://dx.doi.org/10.5430/jnep.v3n1p40
}

\section{Abstract}

Background /Objective: Sixty percent of all smokers in the United States (U.S.) try smoking cigarettes before they are 18 years old. Family and peer behavior (subjective norm), and attitude may influence young people to initiate smoking. The aims of this study were to 1 ) determine if attitude, subjective norm, and knowledge could predict smoking behaviors; 2) identify reasons for smoking; 3) determine if there were differences in attitudes toward smoking between smokers and non-smokers; and 4) determine smokers' intent to quit.

Methods: The population of interest included individuals age 30 or younger. The instrument, in the form of an online Tobacco Survey, was distributed via email, Facebook ${ }^{\circledR}$, and other social media. The survey was created on Survey Monkey.com ${ }^{\circledR}$. Data were collected for nine months and analyzed using SPSS ${ }^{\circledR}$ version 17 for Windows ${ }^{\circledR}$.

Results: Cronbach's alpha for the primary factors were high to adequate, attitude $\mathrm{a}=.89$, knowledge $\mathrm{a}=.71$, and subjective norm $\mathrm{a}=.67$. Results suggested subjective norm and attitude may predict smoking but knowledge was not a predictor. Over $70 \%$ of the smokers tried their first cigarette before the age of 18 years. Most reported reasons for smoking were alcohol consumption, smoking with friends in social settings, stress relief, and relaxation. Seventy-five percent of the smokers agreed that smoking was addictive and knowledge was high regarding the hazards of smoking. Less than 50\% of the smokers planned to quit within the next year.

Conclusions: Tobacco use among adolescents and young adults may be directly influenced by overall attitude and peer and family smoking behaviors. Knowledge of the hazards of smoking does not appear to influence smoking behaviors; therefore it is recommended health care providers, and others in a position to influence young people, focus on changing attitudes about smoking.

\section{Kew words}

Smoking, Adolescents, Young adults, Attitudes, Behaviors, Knowledge

\section{Background}

Smoking is an epidemic in the United States where 3,800 persons a day under 18 years of age attempt smoking cigarettes (1.4 million per year); almost $90 \%$ are daily smokers by the age of 18 years, and $99 \%$ of all smokers are habitual smokers 
by the age of 26 years ${ }^{[1]}$. The Substance Abuse and Mental Health Services Administration ${ }^{[2]}$ reported in 2007 that 70.9 million Americans 12 years and older were current tobacco users; 24.2\% (60.1 million) were current tobacco smokers; $5.4 \%$ (13.3 million) were cigar smokers; and .08\% (2 million) were pipe smokers. Sixty percent of new smokers were younger than 18 years old when they first tried cigarettes. Among these, 6 million or more are expected to die prematurely from a smoking-related disease ${ }^{[3]}$. Figure 1 defines the risk factors for young adult or adolescent initiation of smoking.

The Centers for Disease Control (CDC) [1] cite the

following risk factors for young adult or adolescent

initiation of smoking:

- Low socioeconomic status

- Exposure to smoking in movies

- Lack of skills to resist influences promoting tobacco use

- Smoking by parents or guardians and/or lack of parental support or involvement

- Accessibility, availability, and cost

- A perception that tobacco use is the norm

- Low academic achievement

- Low self-esteem or self-image

- Exposure to tobacco advertising

- Aggressive behavior

- Use and approval of tobacco by peers and siblings

Figure 1. Risk factors for young adult or adolescent initiation of smoking

The consequences of smoking are all negative and include increased resting heart rate, shortness of breath, reduced lung capacity, and increased risk for use of alcohol, marijuana, and cocaine. Adolescent smokers have a greater likelihood of participating in fighting and/or having unprotected sex ${ }^{[4]}$. Cigarette smoking is linked to cataracts and pneumonia, and cancer of the mouth, pharynx, larynx, esophagus, stomach, pancreas, cervix, kidney, bladder, and chronic bronchitis and emphysema. Smoking and second hand smoke exacerbate asthma ${ }^{[3]}$. Use of cigarettes may lead to nicotine addiction ${ }^{[3]}$ characterized by compulsive use despite knowledge of negative effects and experience of negative outcomes. Almost $85 \%$ who try to quit smoking relapse because of addiction ${ }^{[3]}$.

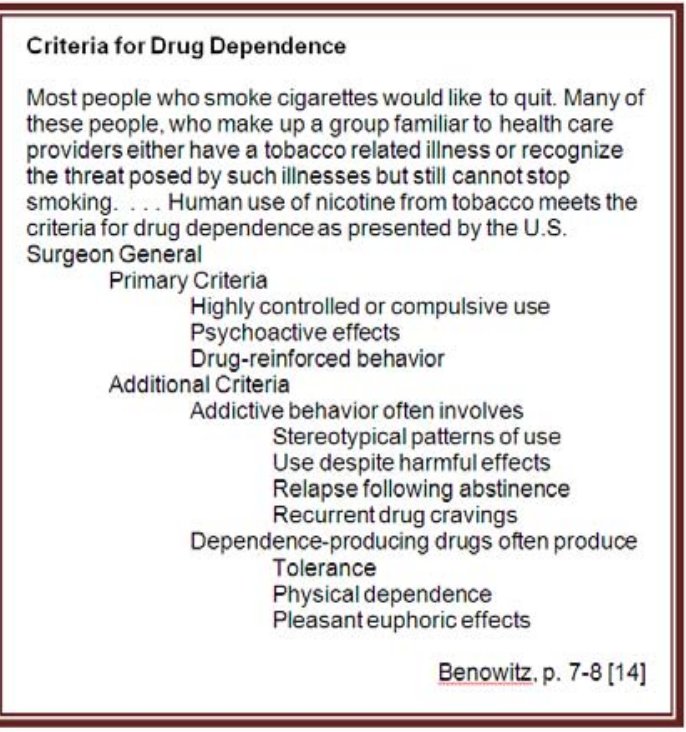

Figure 2. Criteria for Drug Dependence 
In a classic publication on nicotine's safety and toxicity, Benowitz ${ }^{[5]}$ clearly defined the criteria for drug dependence (see Figure 2). Nicotine intake is moderated by positive and negative reinforcement. Positive reinforcement is related to reduced stress and increased relaxation in addition to "enhanced vigilance, improved cognitive function, mood modulation, and lower body weight” (p. 9). Negative reinforcement is related to withdrawal symptoms when one tries to quit, i.e., nervousness, impaired concentration and cognitive function, anxiety, irritability, increase in appetite, and weight gain. Nicotine tolerance, as with many other drugs, increases with use and it takes more of the substance to maintain the same physiological high over time.

\subsection{Theoretical framework}

According to Fishbein and Ajzen's Theory of Planned Behavior (TPB) and the Theory of Reasoned Action (TRA) ${ }^{[6]}$, there are fundamental factors that influence a person's behavior; these include attitude, subjective norm, perceived personal control, and intent related to the behavior. Theoretically, a person is most likely to adopt a behavior if he or she has a positive attitude toward the behavior, views the behavior as normal (i.e., family members, peers, and the media suggest that it may be a normal every day activity), has control over whether or not he or she participates in the behavior, and if it is his or her intention to adopt this behavior in the future. In the case of smoking, ease of access is a factor related to control.

\subsection{Literature review}

\subsubsection{Access}

Leatherdale ${ }^{[7]}$ studied tobacco access of adolescents living in Ontario and Toronto, Canada. The sample included 2,787 13-18 year old students. Of the regular smokers $(n=2,050), 52 \%$ were males and $48 \%$ were females; $71 \%$ of their fathers, $60 \%$ of their mothers, and $9.5 \%$ of their siblings smoked. Sixty percent $(60 \%)$ purchased their own cigarettes from retailers, 33\% had someone else buy them, and approximately 7\% purchased them from another individual. More than one third of them (38.1\%) had never been asked for proof of legal age when purchasing cigarettes. Leatherdale's conclusion (consistent with Craig and Boris ${ }^{[8]}$ ) stated that limiting access through purchasing restrictions, does not always work since adolescents have other means of acquiring cigarettes.

Ma, Shive, Legos, and Tan ${ }^{[9]}$ found that among a group of Philadelphia 8th-10th graders, Hispanics and Whites were more likely to get cigarettes from their friends compared to Asians or Black students. White students were more likely to obtain cigarettes from their family and through self-purchase. Cousins were the most likely family source followed by siblings. This group of students believed it was easy to access cigarettes from vending machines, peers, and retail markets. Among this sample $49.5 \%$ had tried smoking by the 10 th grade, $19.3 \%$ had smoked in the past month, $16.9 \%$ smoked weekly, and 15.2\% smoked daily. Parental sanctions for smoking were more likely to occur among the White students (i.e., being grounded $\left.X^{2}=31.1, \mathrm{p}<.001\right)$. In this study, White students were more likely to use cigarettes daily compared to African American students $\left(\mathrm{F}_{[3,307]}=3.69, p<.01\right)$.

Seo, Macy, Torabi, and Middlestadt ${ }^{[10]}$ conducted a longitudinal study of two campuses. Base line data were collected at both schools. One year after eliminating access and availability of places to smoke on one campus (implementing a smoke-free policy) researchers found significant positive changes; smoking decreased from $16.5 \%$ to $12.8 \%(p<.001)$, and perceptions of tobacco use declined significantly. These factors were significantly more favorable than those on the smoking allowed campus.

\subsubsection{Attitude}

Larsen and Cohen ${ }^{[11]}$ looked at positive and negative attitudes toward smoking to determine if attitudes predicted smoking behaviors. They studied two groups of students in two separate studies. The first study found that among 181 smokers, there were more negative feelings about smoking than positive feelings $\left(X^{2}=78.57, p<.001\right)$. They established that ambivalence toward smoking (equal positive and negative responses) was highly correlated with smoking $r_{[27]}=.48$. A 
positive attitude toward smoking predicted how much someone smoked in the past but a negative attitude did not predict past or current smoking behavior $\left(r_{[181]}=.24, p<.001\right.$ and $r_{\text {[181] }}=-.06$ respectively). Ma et al. ${ }^{[9]}$ also found a strong correlation between tobacco use and attitudes $\left(r_{[633]}=.31, p<.001\right)$.

The second ${ }^{[11]}$ study was longitudinal to determine if positivity and negativity could predict intent and future behaviors. Their final sample included 154 college students who smoked. The findings of this study supported the first that ambivalence may be a strong predictor of smoking behavior over time. They also found that a positive attitude was likely to predict individual's active smoking behavior in the past and in the future.

\subsubsection{Subjective norms}

A 2005 study of Washington state 3rd grade students ${ }^{[12]}$ looked at whether family smoking behaviors could predict children's transition from trying smoking to daily smoking. What Bricker et al. found was that family smoking behaviors were major influences in the younger child's (1) initiating or trying smoking the first time, (2) transitioning from trying to monthly smoking, and (3) transitioning from monthly to daily smoking. Ma et al. found strong positive correlations between subjective norm and perceived availability and there were strong inverse correlations between perceived parental sanctions and smoking ${ }^{[9]}$. Other research supports that subjective norm influences smoking behavior ${ }^{[10-14]}$.

\subsubsection{Knowledge}

Research by Rosendahl et al. ${ }^{[13]}$ found "essentially" no correlation between knowledge and future tobacco use even though $95 \%$ of the children in their sample reported knowing the hazards of smoking by age eleven. Ninth graders in their study admitted to using cigarettes or smokeless tobacco weekly for three months or more (males: $n=1014,34.3 \%$ | females: $n=970,30 \%$ ); others admitted to smoking and using smokeless tobacco at least monthly (males: $n=1,078$, $26.3 \%$ | females: $n=1,139,23.5 \%$ ). Ma et al. ${ }^{[9]}$ found a strong correlation between certainty that one could (easily) quit smoking (shown to be incorrect knowledge) and tobacco use $(r=.32, p<.001)$.

\subsection{Purpose of this study}

The aims of this study were to 1) determine if attitude, knowledge, and subjective norm would predict smoking behaviors; 2) identify reasons for smoking; 3) determine if there was a difference in attitudes toward smoking between smokers and non-smokers; and 4) determine a smoker's intent to quit. The population of interest was young people 30 years old or younger.

\section{Methods}

This project, an online survey design, was approved by the University's Institutional Review Board for the Protection of Human Subjects in September, 2011. Email and social media were used to reach potential respondents but the survey responses were anonymous. No identifying information was included on the surveys. Information was provided about the study and consent was implied if one participated.

\subsection{Search methods}

In addition to the secondary sources ${ }^{[1-6]}$, a review of the empirical literature was facilitated using EBSCO Host, Science Direct, ProQuest, and PubMed. Search words included tobacco, prediction, attitude, adolescents, smoking, behavior, cigarettes, peers, and access.

\subsection{I nstrument}

The instrument was developed by the researchers to measure attitude, behavior, knowledge, and subjective norm related to smoking cigarettes. Attitude was measured by collapsing 14 Likert items (Cronbach's $a=.89$ ); three of these items were 
reversed for consistency. Behavior was determined by dichotomizing eight items related to smoking behavior. Intent was measured using a Likert scale but only questioned one's intent to quit smoking. Subjective norm was determined by collapsing eight Likert items (Cronbach's a $=.67$ ). Knowledge was measured by six Likert items (Cronbach’s a $=.71$ ). Additional data included level of education, age, gender, perceived health, pre-existing conditions, and number of yearly medical visits. Narrative data also asked "What factors influenced your decision to smoke?", "What motivated you to quit smoking in the past or would motivate you to quit smoking now?", and "Additional comments about smoking." The survey can be reviewed at https://www.surveymonkey.com/s/tobac.

\subsection{Validity and reliability}

Internal and external validity for this instrument needs to be confirmed. Validity may be challenged as the instrument only questioned individuals about their behaviors related to smoking cigarettes and did not address the use of smokeless tobacco, pipes, or cigars. External validity is limited to those who may be using the internet and social media and to those living in California given the high California response rate. Further testing of the instrument is required.

\subsection{Data collection and sampling}

The population of interest was people 30 years old or younger. However, data were collected from anyone who chose to complete the online survey. The total sample included 450 respondents, 375 were age 30 years old or younger. For the purpose of this study, data were segregated based on age prior to data analysis.

Sampling was achieved and participants were recruited through social networking. The social media sources used were email, Facebook ${ }^{\circledR}$, Twitter ${ }^{\circledR}$, and Instagram ${ }^{\circledR}$. Each participant was encouraged to post the survey on their Facebook ${ }^{\circledR}$ page and to network with friends to identify additional participants.

Facebook ${ }^{\circledR}{ }^{[15]}$ was the primary source for survey link distribution and a public Facebook ${ }^{\circledR}$ page was created for the research study ${ }^{[16]}$. An open Facebook ${ }^{\circledR}$ event was created explaining intent of the study. Facebook ${ }^{\circledR}$ friends were invited to the event and anyone who joined the event could invite others to participate. The event also had a link to the survey and to the Facebook ${ }^{\circledR}$ page. The link to the survey was sent in Facebook ${ }^{\circledR}$ messages and posted on profiles of participants who chose to make the survey available to their friends.

Twitter ${ }^{\circledR}$ is a social network that allows users to share recent accounts and events ${ }^{[17]}$. A Twitter ${ }^{\circledR}$ profile was created for the research study with a link to the survey ${ }^{[18]}$ Tweets, comments with 140 characters ${ }^{[17]}$, were posted with relevant hashtags. The \# symbol, called a hashtag, was used to mark keywords in a Tweet and to categorize messages ${ }^{\text {[19] }}$. The survey's link was also shared on one researcher's personal Twitter ${ }^{\circledR}$ profile.

Instagram ${ }^{\circledR}$ is a social network primarily used for photo sharing, where users can upload photographs from cell phone cameras. A link to the survey was posted on one researcher's personal Instagram ${ }^{\circledR}$ profile. Pictures were posted with relevant hashtags. Hashtag words included nursing, research, nursing research, tobacco, smoke, smoking, smokers, nonsmoker, Dominican University of California, anonymous, survey, Surveymonkey, social networking, and participants.

The authors' goal was to collect 1,500 responses. A reasonable amount of effort was put into collecting this data through network sampling and using social media venues, but no extreme measures were used such as purchasing lists or using a sampling service. Data were collected for nine months.

\subsection{Data analysis}

The data were analyzed using SPSS ${ }^{\circledR}$ v. 17 for Windows ${ }^{\circledR}$. Surveymonkey ${ }^{\circledR}$ has a feature that allows data to be exported to SPSS ${ }^{\circledR}$. Data were cross-checked between the SPSS ${ }^{\circledR}$ file and the Surveymonkey ${ }^{\circledR}$ summary of the findings. 


\section{Results and findings}

\subsection{Demographics}

Findings are reported for individuals who were 30 years old or younger ( $n=375,82.6 \%$ of the total sample). Of this group, 281 (74.9\%) were female, 93 (24.8\%) were male, and one person identified as transgender female (.3\%). The mean age of both the non-smokers and the smokers was 22 . The average age respondents first tried smoking was 15.9 years $(\mathrm{SD}=2.81$, range 8 to 24 years). Among the smokers who responded ( $n=43), 72.1 \%$ started smoking before they could legally purchase cigarettes (age 18 years in the U.S.) (see Table 1 ).

Table 1. How old were you when you first tried smoking?

\begin{tabular}{lll}
\hline Age & Freq & Cumulative (\%) \\
\hline 8 & 1 & 2.3 \\
9 & 1 & 4.7 \\
13 & 5 & 16.3 \\
14 & 5 & 27.9 \\
15 & 7 & 44.2 \\
16 & 4 & 53.5 \\
17 & 8 & 72.1 \\
18 & 8 & 90.7 \\
19 & 2 & 85.3 \\
21 & 1 & 97.7 \\
24 & 1 & 100.0 \\
Total & 43 & \\
Missing & 12 & \\
\hline
\end{tabular}

Note: Smokers make up $14.6 \%$ of the total sample. Mean=15.91 SD=2.81

Seventy percent of the smokers in this study obtained their first cigarette from a family member or friend; $30 \%$ purchased, stole, or somehow obtained cigarettes on their own. Ninety percent of the respondents were from California; 22 other states were minimally represented with the second highest number of responses from Virginia (2.2\%). Non-U.S. participants were from Canada, Australia, the Republic of Panama, Malaysia, Philippines, Taiwan, and New Zealand.

Non-smokers rated their overall health better than smokers $\left(\mathrm{F}_{[1,372]}=6.564, p=.01\right)$. Additionally, smokers were three times as likely to visit a physician or nurse practitioner more than five times a year compared to non-smokers (15.6 vs. 4.6\%); the difference was significant $\left(\mathrm{F}_{[1,371]}=12.51, p=.000\right)$. There was no difference in education between the two groups. Gender did not predict smoking behavior.

\subsection{Attitudes}

ANOVA was used to compare smokers and non-smokers and found a significant difference in attitudes towards smoking where the smokers had the more positive attitude $\left(\mathrm{F}_{[1,335]}=139.64, p=.000\right)$. Logistic Regression found that attitude toward smoking was a significant predictor of smoking behavior $\left(\beta=1.767\right.$, SEB $=.150$, Wald's $X^{2}=11.817, p=.000$, adjusted $\mathrm{R}^{2}=.293$ ). The details, means, and standard deviation for the disaggregated data for attitudes are in Table 2 . 
Table 2. Attitudes toward Smoking

\begin{tabular}{lll}
\hline Statements & $\begin{array}{l}\text { Mean / SD } \\
\text { Smokers (46) }\end{array}$ & $\begin{array}{l}\text { Mean / SD } \\
\text { Non-Smokers (290) }\end{array}$ \\
\hline Smoking looks cool. & $2.65 / 1.15$ & $1.66 / 1.01$ \\
I do not like being around others who smoke. & $3.89 / 0.93$ & $2.06 / 1.20$ \\
Tobacco smoke does not bother me. & $3.50 / 1.20$ & $1.93 / 1.22$ \\
People should be able to smoke tobacco if they like. & $4.06 / 0.93$ & $3.19 / 1.19$ \\
I disapprove of non-smoking policies on school grounds. & $3.00 / 1.58$ & $1.84 / 1.23$ \\
Tobacco companies should be able to advertise freely. & $3.06 / 1.30$ & $2.21 / 1.10$ \\
I intend to smoke when I get older. & $2.52 / 1.26$ & $1.23 / 0.55$ \\
If offered a cigarette I might smoke it. & $4.17 / 0.80$ & $1.54 / 1.00$ \\
People should be able to smoke in bars. & $2.84 / 0.51$ & $2.00 / 1.12$ \\
People should be able to smoke in restaurants. & $2.30 / 1.47$ & $1.66 / 1.22$ \\
Tobacco taxes are too high. & $3.71 / 1.33$ & $2.14 / 1.07$ \\
Tobacco use is less of a problem than illegal drug use. & $3.04 / 1.56$ & $2.14 / 1.07$ \\
\hline
\end{tabular}

Note. All differenceswere significant at the .05 level or less. (1=strongly disagree, $2=$ disagree, $3=$ unsure, $4=$ agree, $5=$ strongly agree; data treated as scale)

\subsection{Subjective norm}

ANOVA of the collapsed values for subjective norm revealed that smokers were more likely to have friends and family who smoked and considered smoking to be the norm compared to the non-smoker $\left(\mathrm{F}_{[1,261]}=21.133, p=.000\right)$. Subjective norm was a strong predictor of smoking behavior with an adjusted $\mathrm{R}^{2}=.221$. The strongest predictors were friends smoking $(p=.000)$, spouse smoking ( $p=.029)$, and agreeing that most people smoke $(p=.045)$.

One participant stated, "I always knew I was going to be a smoker because both my grandmas were heavy smokers and [I] was raised being around smoking." Another participant stated, "I saw my parents smoking growing up as a child, and as an adult I didn’t think there was anything wrong with smoking.”

\subsection{Knowledge}

Smokers were almost half as likely to strongly agree (SA) that smoking is bad for your health (non-smokers $=91.3 \%$ | smokers $=54.5 \%$ ). Smokers were less likely to SA that secondhand smoke is bad for your health (non-smokers $=83.03 \%$ | smokers $=47.7 \%$ ). The smokers were less likely to SA that smoking dries your skin and causes you to look older (non-smokers $67.1 \% \mid$ smokers $=34.1 \%$ ). They were less likely to SA that smoking causes cancer (non-smokers $=83.7 \%$ | smokers $=54.5 \%$ ) and less likely to SA that people who smoke are more likely to use other drugs (non-smoker $=28.4 \%$ | smoker $=18.2 \%$ ).

While the non-smokers had more correct answers, the smokers still had high rates of correct answers when agree and strongly agree were combined (SA/A). For example 95\% of the smokers SA/A that smoking is bad for your health; $84 \%$ SA/A that second hand smoke is bad for one's health; $84.1 \%$ SA/A that smoking contributes to dry skin and aging; and $20.4 \%$ SA/A that if one quit smoking lungs could be back to normal within ten years. Ninety-seven percent (97.7\%) SA/A that smoking causes cancer.

\subsection{Behavior and reasons for smoking}

Figure 3 identifies the smoking behaviors of the entire sample of young adults. The reasons they gave for smoking are detailed in Table 3. 


\section{Please select the option that most likely applies to you.}

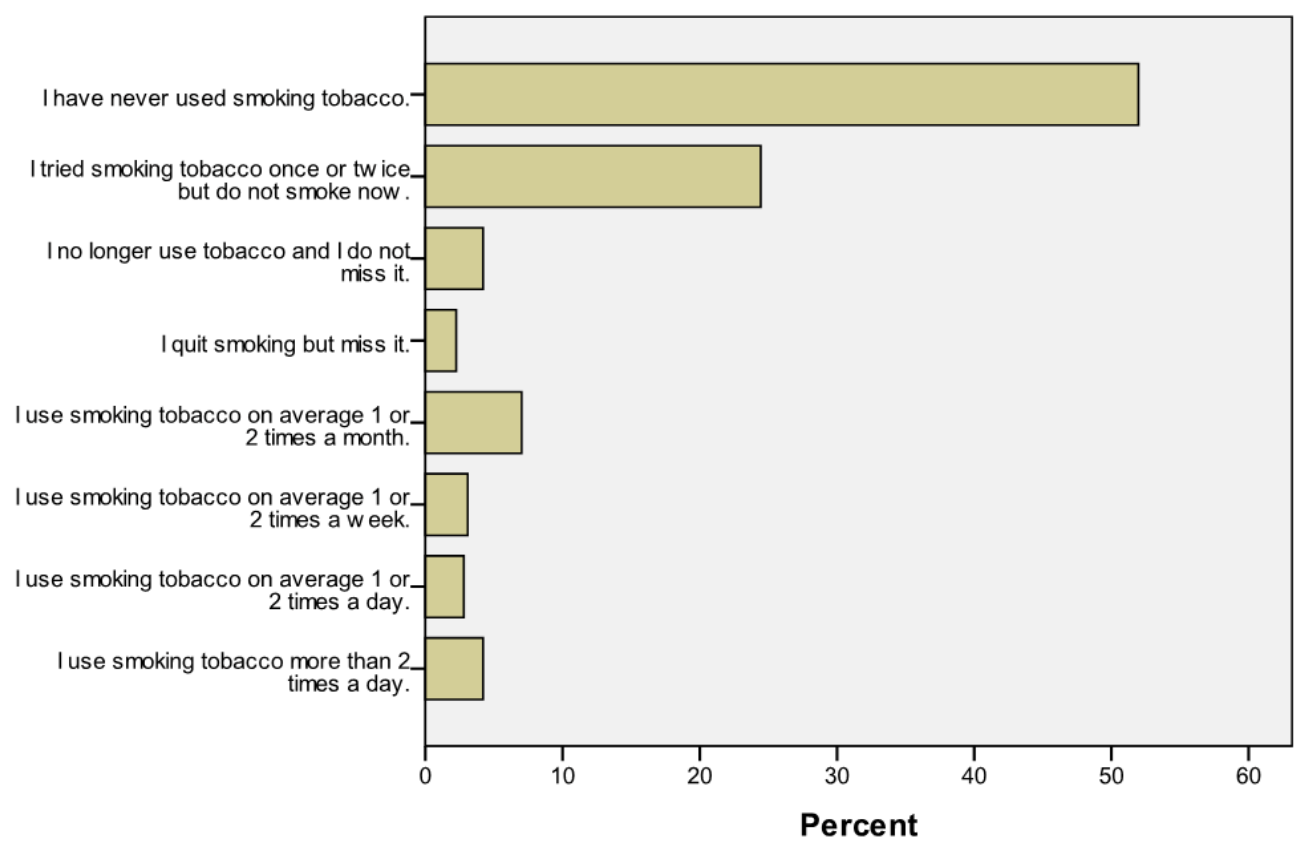

Figure 3. Smoking Behaviors

Table 3. Reasons Given for Smoking (percentage of responses) $n=47$

\begin{tabular}{llcc}
\hline Statements & $\begin{array}{l}\text { Disagree or } \\
\text { strongly disagree }\end{array}$ & Unsure & $\begin{array}{l}\text { Agree or } \\
\text { strongly agree }\end{array}$ \\
\hline Smoking cigarettes helps me to stay thin. & 59.6 & 21.3 & 19.1 \\
I like smoking cigarettes when I drink alcoholic beverages. & 0.0 & 4.3 & 95.7 \\
I am more likely to smoke when I drink alcoholic beverages. & 6.4 & 2.1 & 91.5 \\
I smoke cigarettes when I am nervous or stressed. & 34.0 & 23.4 & 42.6 \\
Smoking cigarettes helps me to relax. & 6.5 & 10.9 & 82.6 \\
Smoking cigarettes gives me a high. & 34.0 & 23.4 & 42.6 \\
I feel good when I am smoking cigarettes. & 23.4 & 31.9 & 44.7 \\
I feel happy smoking cigarettes. & 24.4 & 40.4 & 35.2 \\
Cigarette ads influence me to smoke. & 80.9 & 10.6 & 8.5 \\
Seeing movie stars and important people smoking influences me to smoke. & 70.2 & 12.8 & 17.0 \\
I like smoking cigarettes with my friends. & 4.3 & 17.0 & 78.8 \\
I smoke when I am bored. & 43.8 & 12.8 & 40.4 \\
Nicotine is addictive. & 20.0 & 8.9 & 71.1 \\
\hline
\end{tabular}

\subsection{I ntent to quit}

Table 4 details the smokers' intentions to quit smoking. Forty nine percent (48.8\%) smoked cigarettes but did not think they were addicted; $47 \%$ had tried to quit smoking but were unsuccessful; $44 \%$ intended to quit smoking within the year. When asked what would motivate one to quit smoking, a participant stated, "Being healthier, saving money and feeling generally better about my decisions! I believe it has to be self motivated.” 
Table 4. Intention to Quit Smoking (percentage of response) $n=47$

\begin{tabular}{llll}
\hline Statements & $\begin{array}{l}\text { Disagree or } \\
\text { strongly disagree }\end{array}$ & Unsure & $\begin{array}{l}\text { Agree or } \\
\text { strongly agree }\end{array}$ \\
\hline I like smoking and do not want to quit at this time. & 9.8 & 29.3 & 48.73 \\
I smoke cigarettes but I am not addicted. & 39.0 & 12.2 & 48.8 \\
I would like to quit smoking but have never really tried. & 60.0 & 20.0 & 20.0 \\
I wish I could quit smoking cigarettes but know I cannot quit. & 68.3 & 24.4 & 7.3 \\
I have tried to quit smoking but was unsuccessful. & 46.3 & 7.3 & 46.4 \\
I am trying to quit smoking at this time. & 56.1 & 22.0 & 22.0 \\
I plan to quit smoking cigarettes within six months. & 39.0 & 26.8 & 34.1 \\
I smoke cigarettes now but intend to quit within the year. & 31.7 & 24.4 & 43.9 \\
\hline
\end{tabular}

\subsection{Narrative responses}

In the narrative responses, one 18 year old female who said she smoked once or twice a day, commented, "I do not need to quit, I am not addicted - my body my decision.” This young woman also agreed that smoking and second hand smoke were bad for her health and that smoking causes premature aging and cancer. She rated her health 9, but said that she sees a medical practitioner 5 or more times a year.

One 24 year old man wrote, "If I could go back to high school, I would have never tried it. I'm sick of smoking." A 21 year old female wrote, "I am not proud of smoking the occasional cigarette, but sometimes when in the social setting it is tempting.” Some were adamant that smoking was a personal right, as one 19 year old female wrote, “Smoking isn't that big of deal if people do it in moderation. People should be free to smoke on college campuses and in bars, if it bothers certain people in those settings, they who are bothered should just leave. I don't smoke personally, but it's not a terrible thing. Yes, I know it causes cancer, but we shouldn't be telling smokers not to smoke. If it's so horrible, why are tobacco companies still in business? Drinking causes more deaths than smoking, so we should focus on alcohol.” The negative comments about smoking far outweighed the positive comments by a ratio of about ten to one. Other narrative data suggested that the most important reasons to consider quitting smoking were health, the possibility of cancer, family considerations, and expense of smoking.

\section{Discussion and conclusions}

Similar to other research findings, $72.1 \%$ of the smokers in this study reported trying their first cigarette before the age of 18 years. Also consistent with other research, they obtained their cigarettes from family, friends, and by purchasing or stealing them; these respondents seemed to have easy access to cigarettes. Not surprisingly, smokers' attitudes toward smoking were more favorable than non-smokers, and they were less supportive of policies that restricted smoking in restaurants, in bars, and on school grounds or that taxed tobacco products.

The findings of this study support the theory that attitude and subjective norm are predictors of smoking behavior. However, consistent with the research by Rosendahl et al. ${ }^{[13]}$, knowledge about the hazards of smoking does not seem to influence smoking behavior once smoking has been initiated. Almost 100\% (43/44) said that they agreed or strongly agreed that smoking cigarettes causes cancer but they still smoked. This likely has to do with the addictive properties of nicotine. Smokers reported failed attempts at cessation and reported side effects of smoking consistent with criteria for drug dependence. Of this sample, $46 \%$ had tried to quit smoking and failed, $45 \%$ agreed they felt good when smoking, $43 \%$ said smoking gave them a high, $71 \%$ said that nicotine was addictive, yet $49 \%$ said that they were not addicted.

The goals of this study were achieved but further research should be conducted with a larger and more diverse sample looking at other tobacco use behaviors (i.e., use of smokeless tobacco, pipes, and cigars), making additional comparisons 
between states with and without state-wide smoking bans, and longitudinal studies of young adults and their successes and challenges in tobacco use cessation.

\section{I mplications for nursing practice and patient education}

Nurses, educators, and health professionals are in occupations where they have daily contact with the public. These individuals should continue to report the negative health effects of smoking but perhaps put more effort into modeling attitudes that make smoking seem less attractive or alluring, especially to the very young who have yet to try cigarettes.

Also, given that subjective norm is a strong predictor, focusing on parents' behaviors would likely reduce smoking initiation among young people. Creating and disseminating information to parents about the effect their smoking habits have on children's smoking behaviors, along with smoking cessation materials, may influence parents to quit smoking or reduce their cigarette consumption when around their children, i.e., banning smoking in the home and in the car. Keeping cigarettes out of sight in the home may help to reduce young peoples' curiosity about smoking and thoughts about trying it.

These research findings are consistent with information provided by the CDC ${ }^{[1]}$ and $\mathrm{WHO}{ }^{[4]}$ that use and approval of cigarettes by peers, siblings, and parents may influence cigarette smoking by young people. This being the case educators and health providers should offer appropriate education to all family members. Additionally, implementing tobacco-free campus policies and educating young people about the implications of addiction may reduce early initiation of cigarette smoking. According to one participant, "It's a choice, but once you're addicted it's less of a choice...I think one of the reasons I started smoking was I didn’t know quite how addictive it was until it was too late.”

\section{Limitations}

Limitations of this study included sample size and uncertainty about percentage of responses. Since the survey was posted on Facebook ${ }^{\circledR}$ and other social media, and network sampling was employed, it is unclear what percentage of the accessible population participated. Further, given that this sample was primarily from California, the findings may be biased and cannot be generalized to other states. Respondents who did not have social media or email accounts were not included in the sampling. Researchers have no way of knowing if the individuals who expressed a desire to quit smoking actually did quit smoking. Another limitation was the lack of consideration given to other forms of tobacco such as cigars, pipes, and chewing tobacco. Validity and reliability is an issue that should have been given greater consideration and needs to be addressed in future research. Questions of behavior need to be vetted; two respondents thought some questions were unclear in terms of "cigarette smoking” and "tobacco use".

\section{References}

[1] U.S. Department of Health and Human Services (USDHHS). Preventing tobacco use among youth and young adults: a report from the Surgeon General [Internet]. Atlanta, GA: U.S. Department of Health and Human Services, Centers for Disease Control and Prevention, National Center for Chronic Disease Prevention and Health Promotion, Office on Smoking and Health, 2012. Available from: http://www.surgeongeneral.gov/library/reports/preventing-youth-tobacco-use/exec-summary.pdf

[2] Substance Abuse and Mental Health Services Administration. Results from the 2007 National Survey on Drug Use and Health: National Findings. DHHS Pub. No. SMA 08-4343. Rockville, MD: Office of Applied Studies, 2008.

[3] USDHHS, National Institutes of health, National Institute on Drug Abuse. Research report series tobacco addiction. NIH publication number 09-4342. 2009.

[4] World Health Organization. Health effects of smoking on young people [Internet]. Available from: http://www.who.int/tobacco/research/youth/health_effects/en/, 2012.

[5] Benowitz NL. Nicotine pharmacology and addiction. In Nicotine Safety and Toxicity, toxicity. N. L. Benowitz ed. New York: Oxford University Press. 1998; 7-8. 
[6] Montano, DE and Kaspryzk, D. Theory of Reasoned Action, Theory of Planned Behavior, and the Integrated Behavioral Model. In Health Behavior and Health Education, Theory, Research, and Practice. K. Glanz, B.K. Rimer, and K. Viswanath eds. San Francisco: Jossey-Bass. 2008; 67-97.

[7] Leatherdale ST. Predictors of different cigarette access behaviors among occasional and regular smoking youth. Canadian Journal of Public Health. 2005; 96: 348-352. PMid:16238152

[8] Craig MJ, Boris NW. Youth tobacco access restrictions: time to shift resources to other interventions. Health Promotions Practice 2007; 8: 22-27. PMid:16840766 http://dx.doi.org/10.1177/1524839905279882.

[9] Ma GX, Shive S, Legos P, Tan Y. Ethnic differences in adolescent smoking behaviors, sources of tobacco, knowledge and attitudes toward restriction policies. Addictive Behaviors. 2003; 28: 249-268. http://dx.doi.org/10.1016/S0306-4603(01)00225-8

[10] Seo DC, Macy JT, Torabi MR, Middlestadt SE. The effect of a smoke-free campus policy on college students' smoking behaviors and attitudes. Preventive Medicine. 2011; 53: 345-352.

[11] Larsen JT, Cohen LM. Smoking attitudes, intentions, and behaviors among college student smokers: positivity outweighs negativity. Addiction Research and Theory. 2009; 17: 637-649. http://dx.doi.org/10.3109/16066350802068854

[12] Bricker JB, Peterson AV, Leroux BG, Andersen MR, Rajan KB, Sarason IG. Prospective prediction of children's smoking transitions: role of parents' and older siblings' smoking. Society for the Study of Addiction. 2005; 101: 128-136. PMid:16393199 http://dx.doi.org/10.1111/j.1360-0443.2005.01297.x

[13] Rosendahl KI, Galanti MR, Gilljam H, Ahlbom A. Knowledge about tobacco and subsequent use of cigarettes and smokeless tobacco among Swedish adolescents. Journal of Adolescent health. 2005; 37: 224-228. PMid:16109342 http://dx.doi.org/10.1016/j.jadohealth.2004.08.021

[14] Book JS, Saar NS, Zhang, C, Brook DW. Familial and non-familial smoking: effects on smoking and nicotine dependence. Drug and Alcohol Dependence. 2008; 101: 62-68. PMid:19101100

[15] Facebook [Internet]. Available from: http://dictionary.reference.com/browse/facebook.

[16] Collecting Tobacco Information via Social Networking [Internet]. Available from: http://www.facebook.com/pages/Collecting-Tobacco-Information-via-Social-Networking/249110875125634.

[17] Twitter [Internet]. Available from: https://twitter.com/about

[18] Nurs Research Tobac [Internet]. Available from: https://twitter.com/nursresrchtobac.

[19] What Are Hashtags (“\#” Symbols)? [Internet]. Available from: https://support.twitter.com/articles/49309-what-are-hashtags-symbols.

[20] Instagram [Internet]. Available from: https:// http://instagram.com/. 